\title{
Analytical Model of Waterflood Sweep Efficiency in Vertical Heterogeneous Reservoirs under Constant Pressure
}

\author{
Lisha Zhao, ${ }^{1,2} \mathrm{Li} \mathrm{Li}^{2}{ }^{2}$ Zhongbao Wu, ${ }^{2}$ and Chenshuo Zhang ${ }^{2}$ \\ ${ }^{1}$ School of Earth and Space Sciences, Peking University, Beijing 100871, China \\ ${ }^{2}$ Research Institute of Petroleum Exploration \& Development, PetroChina, Beijing 100083, China \\ Correspondence should be addressed to Lisha Zhao; zhaolisal121@163.com
}

Received 20 June 2016; Revised 27 September 2016; Accepted 25 October 2016

Academic Editor: Jian Guo Zhou

Copyright (c) 2016 Lisha Zhao et al. This is an open access article distributed under the Creative Commons Attribution License, which permits unrestricted use, distribution, and reproduction in any medium, provided the original work is properly cited.

\begin{abstract}
An analytical model has been developed for quantitative evaluation of vertical sweep efficiency based on heterogeneous multilayer reservoirs. By applying the Buckley-Leverett displacement mechanism, a theoretical relationship is deduced to describe dynamic changes of the front of water injection, water saturation of producing well, and swept volume during waterflooding under the condition of constant pressure, which substitutes for the condition of constant rate in the traditional way. Then, this method of calculating sweep efficiency is applied from single layer to multilayers, which can be used to accurately calculate the sweep efficiency of heterogeneous reservoirs and evaluate the degree of waterflooding in multilayer reservoirs. In the case study, the water frontal position, water cut, volumetric sweep efficiency, and oil recovery are compared between commingled injection and zonal injection by applying the derived equations. The results are verified by numerical simulators, respectively. It is shown that zonal injection works better than commingled injection in respect of sweep efficiency and oil recovery and has a longer period of water free production.
\end{abstract}

\section{Introduction}

Heterogeneity is a common problem encountered in oilbearing formations. The most significant property that affects waterflooding performance is the matrix permeability, and its variation in the vertical direction causes displacing fluid to advance faster in zones of higher permeability and results in earlier breakthrough in such layers. This phenomenon negatively affects volumetric sweep efficiency and leads to low ultimate oil recovery [1-5]. Therefore, it is considerably important to establish a quantitative characterization method for calculating sweep efficiency; by this method, we can determine the criteria of dividing and reorganizing layer series and relieve interlayer interference in stratified waterflooding reservoir development.

Vertical sweep efficiency is the fraction of vertical crosssectional area of the reservoir between injection and production wells that is swept by water at a given time. It can be used to estimate and predict the unswept fraction of the reservoir by water injection and the additional oil recovery potential.
Buckley and Leverett [6] presented the fractional flow equation based on mass conservation equation. Welge [7] proposed that waterflood sweep efficiency could be obtained by water cut and water saturation curves. To multilayer reservoirs, Stiles [8] presented the first model for waterflood calculations in stratified reservoirs and assumed velocities in different layers to be proportional to their absolute permeabilities. Later models for noncommunicating layers without crossflow [9-11] and models for communicating layers with complete crossflow $[12,13]$ were carried out. ElKhatib $[14,15]$ investigated the effect of crossflow on the performance of stratified reservoirs and presented a closed form analytical solution for communicating stratified systems with log-normal permeability distributions. Zhou et al. [16, 17] developed a model of linear nonpiston waterflood and calculated the sweep efficiency by production compartment. El-Khatib $[18,19]$ considered the gravity effect of the dip angle to sweep efficiency and Snyder and Ramey [20] improved on previous work while changing the property of layers in a logical and consistent manner. Prince [21] investigated the 


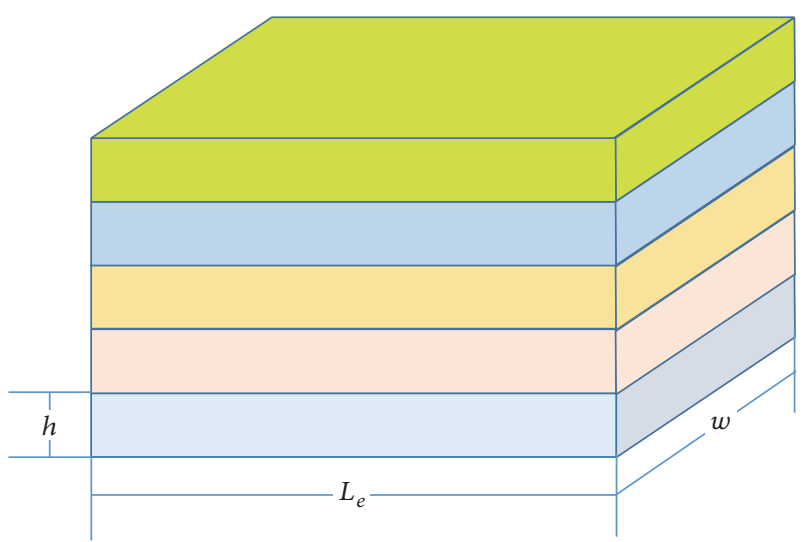

FIgURE 1: Schematic representation of stratified system.

effect of mobility ratio and the Dykstra-Parsons permeability variation coefficient (VDP) on the performance.

Firstly, many of the models mentioned above assumed piston-like displacement when predicting waterflooding performance in stratified reservoirs, which was not consistent with the frontal advance theory. Secondly, the abovementioned study of flooding process was usually based on the condition of constant rate, which provided a constant volume of water injected into each layer by production compartment according to each layer's property. However, for multilayered reservoir development, the production pressure between injection and production well is usually stable, while the rate of liquid produced in each layer is changeable. So, in this model, the reservoir is divided into a number of layers. And each layer is considered as non-piston-like displacement on the condition of constant pressure. A mathematical model is developed for calculating waterflood sweep efficiency by extending the Buckley-Leverett displacement mechanism.

\section{Mathematical Model Building and Assumptions}

Figure 1 is a schematic representation of the stratified system. The production pressure between injection and production well is equal to a constant value: $\Delta P=P_{w f}-P_{\text {inj }}$, where $P_{\text {inj }}$ is the bottom pressure of injection well, $\mathrm{MPa} ; P_{w f}$ is the bottom pressure of producing well, $\mathrm{MPa}, \Delta P$ is the pressure drop from the injection well to producing well, $\mathrm{MPa}$.

The following assumptions are made:

(1) The system is divided into a number of homogeneous layers; each has a uniform thickness and constant permeability.

(2) The system is linear and horizontal and of constant thickness.

(3) The flow is isothermal and incompressible and obeys Darcy's law.

(4) The displacement is non-piston-like with a two-phase region where both oil and water exist.
(5) Capillary and gravity forces are negligible.

(6) The system is noncommunicating with no crossflow allowed between adjacent layers.

(7) The relative permeability characteristics are the same for all layers.

(8) The initial fluid saturation is uniform at the irreducible water saturation.

(9) The porosity is assumed to be constant in all layers.

\section{Calculation for Single Layer}

The performance before displacement front reaches the outlet face is quite identical in each layer. After water breakthrough, injection continues, assuming that the front of displacement remains going forward, and the outlet saturation rises from $S_{w f}$ to $1-S_{o r}$, where $S_{w f}$ is the water saturation of displacement front, $\mathrm{f}$, and $S_{\text {or }}$ is the residual oil saturation, $\mathrm{f}$. Figure 2 illustrates the three stages during waterflooding. This process is split into three subperiods, and piecewise functions of sweep efficiency are deduced with the breakthrough time as the endpoint.

Based on the material balance equation and BuckleyLeverett's frontal advance theory, the total volume of water injected in a given time equals

$$
\begin{aligned}
\int_{0}^{t} Q d t & =\int_{x_{0}}^{x_{f}} \phi w h\left[S_{w}(x, t)-S_{w c}\right] d x \\
& =\phi w h \frac{x_{f}-x_{0}}{f_{w}^{\prime}\left(S_{w f}\right)}
\end{aligned}
$$

where $Q$ is the flow rate of oil, $\mathrm{m}^{3} / \mathrm{s} ; w$ is the width of each layer, $\mathrm{m} ; h$ is the height of each layer, $\mathrm{m} ; \phi$ is the porosity of matrix, $\mathrm{f} ; x_{f}$ is the displacement front position, $\mathrm{m} ; x_{0}$ is the initial position of displacement front, $\mathrm{m} ; f_{w}\left(S_{w}\right)$ is the fractional flow of water, $f$.

The calculation of sweep efficiency in a single layer is given by

$$
\begin{aligned}
\eta & =\frac{\int_{0}^{x_{f}}\left(\left(S_{w}-S_{w c}\right) /\left(1-S_{o r}-S_{w c}\right)\right) h d x}{h L_{e}} \\
& =\frac{\bar{S}_{w}-S_{w c}}{1-S_{o r}-S_{w c}} \cdot \frac{x_{f}}{L_{e}},
\end{aligned}
$$

where $L_{e}$ is the length of model, m. Before water breakthrough, average saturation $\bar{S}_{w}$ is determined by fractional flow curve $\left(f_{w}-S_{w}\right)$ [6], which is a constant value. So, the flooding swept volume is only determined by the position of the water frontal advance; after breakthrough, (2) deforms as follows:

$$
\eta=\frac{\bar{S}_{w}-S_{w c}}{1-S_{o r}-S_{w c}}
$$

where $\bar{S}_{w}$ is no longer a constant and should be determined by the saturation of the producing well $S_{w e}$. Consequently, 


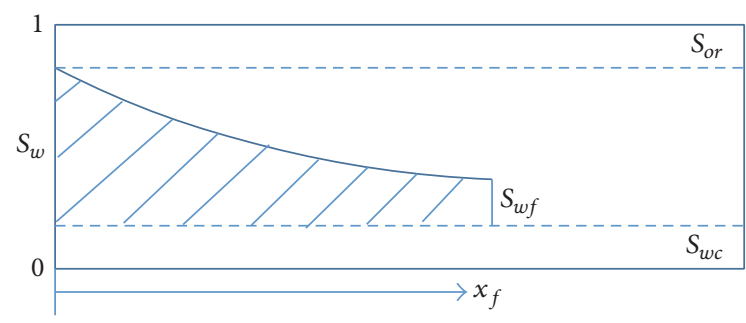

(a) Before water breakthrough

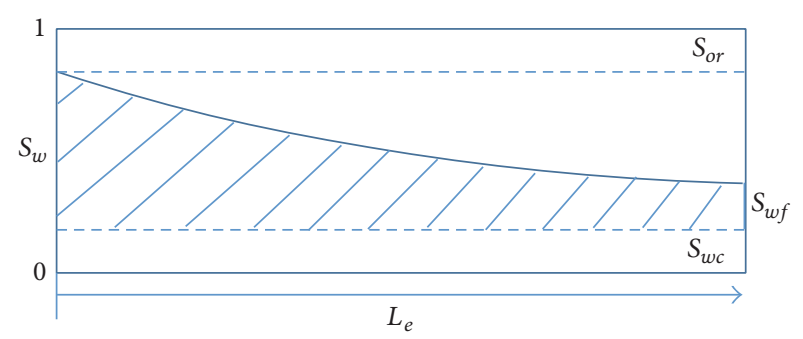

(b) At the time of breakthrough

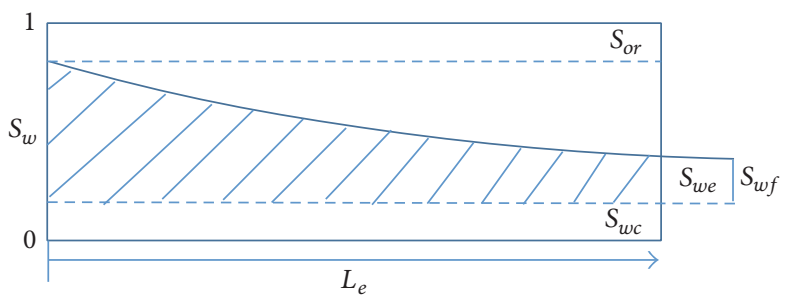

(c) After water breakthrough

FIGURE 2: Different stages during water/oil displacement.

it is necessary to calculate the waterflood front location before breakthrough and the saturation of the outlet face $S_{w e}$ after breakthrough. Firstly, we analyze the waterflooding performance in a single layer by studying the pressure relationship based on the constant pressure condition.

3.1. Pressure in Oil and Water Region. By Applying Darcy's law for a single layer, the total velocity at a certain position $x_{a}$ between injection well and the front location is given by

$$
v=v_{w}+v_{o}=-K\left(\frac{K_{r w}}{\mu_{w}}+\frac{K_{r o}}{\mu_{o}}\right) \frac{d p}{d x},
$$

where $K$ is the absolute permeability, $10^{-3} \mu \mathrm{m}^{2} ; K_{r w}$ is the water relative permeability, f; $K_{r o}$ is the oil relative permeability, $\mathrm{f} ; \mu_{w}$ is the viscosity of water, $\mathrm{mPa} \cdot \mathrm{s} ; \mu_{o}$ is the viscosity of oil, $\mathrm{mPa} \cdot \mathrm{s}$.

Based on the Buckley-Leverett frontal displacement theory, the water cut is expressed as

$$
f_{w}\left(S_{w}\right)=\frac{Q_{w}}{Q_{w}+Q_{o}}=\frac{1}{1+\left(K_{r o} \mu_{w} / K_{r w} \mu_{o}\right)} .
$$

Substituting (5) into (4) and integrating, we obtain the pressure drop between the positions of $x=x_{a}$ :

$$
\Delta P_{a}=P_{a}-P_{\mathrm{inj}}=\frac{v \mu_{w}}{K} \int_{0}^{x_{a}} \frac{f_{w}\left(S_{w}\right)}{K_{r w}} d x .
$$

The location of the injection well is treated as the position of $x=0$, and the frontal displacement function can be written as

$$
x=\frac{f_{w}^{\prime}\left(S_{w}\right)}{\phi w h} \int_{0}^{t} Q d t .
$$

Equation (7) can be deformed as

$$
x=x_{f} \frac{f_{w}^{\prime}\left(S_{w}\right)}{f_{w}^{\prime}\left(S_{w f}\right)} .
$$

From the position of $x=0$ to $x=x_{a}$, the water saturation changes from $1-S_{o r}$ to $S_{w a}$. Substituting (8) into (6), we get

$$
\Delta P_{a}=\frac{v \mu_{w}}{K} \cdot \frac{x_{f}}{f_{w}^{\prime}\left(S_{w f}\right)} \cdot F\left(S_{w a}\right),
$$

where $F\left(S_{w a}\right)$ is given by

$$
F\left(S_{w a}\right)=\int_{0}^{f_{w}^{\prime}\left(S_{w a}\right)} \frac{f_{w}\left(S_{w}\right)}{K_{r w}} d f_{w}^{\prime}\left(S_{w}\right) .
$$

3.2. Time of Water Breakthrough. The pressure drop from the injection well to the displacement front location is defined as $\Delta P_{f}$. Since the average saturation is a constant before water breakthrough, setting $F\left(S_{w f}\right)$ to value $a$ and substituting value $a$ into (9) yield

$$
\Delta P_{f}=P_{f}-P_{\mathrm{inj}}=\frac{v \mu_{w}}{K} \cdot \frac{x_{f}}{f_{w}^{\prime}\left(S_{w f}\right)} \cdot a .
$$

Substituting (7) into (11), we get

$$
\Delta P_{f}=\frac{v \mu_{w} a W(t)}{\phi w h K},
$$

where $W(t)$ represents the accumulated volume of water injected from the time of beginning, and it is equal to the total liquid volume produced from the oil well:

$$
W(t)=\int_{0}^{t} Q d t=\int_{0}^{t} w h v d t .
$$


In the pure oil region, there is only one phase, and the pressure drop of this region is

$$
\Delta P_{o}=\Delta P-\Delta P_{f}=\frac{\mu_{o} v}{K}\left(L_{e}-x_{f}\right)
$$

Substituting (11) and (12) into (14), we get

$$
\Delta P_{f}=\frac{a \Delta P W(t)}{\phi w h \mu_{r} L_{e}-\mu_{r} W(t) f_{w}^{\prime}\left(S_{w f}\right)+a W(t)},
$$

where $\mu_{r}$ is the ratio of oil viscosity and water viscosity, $\mathrm{f}$. Taking the derivative of (13) and substituting it into (12), we obtain

$$
\Delta P_{f}=\frac{\mu_{w} a W(t)}{\phi(w h)^{2} K} \frac{d W(t)}{d t}
$$

Combining (15) with (16) and integrating and rearranging the equation, the accumulated volume of water from $t=0$ to $t=$ $t_{n}$ is obtained:

$$
W\left(t_{n}\right)=\frac{\sqrt{\left(\mu_{o} \phi w h L_{e}\right)^{2}+2\left[\mu_{w} a-\mu_{o} f_{w}^{\prime}\left(S_{w f}\right)\right]\left[\phi(w h)^{2} K \Delta P t_{n}\right]}-\mu_{o} \phi w h L_{e}}{\mu_{w} a-\mu_{o} f_{w}^{\prime}\left(S_{w f}\right)} .
$$

Substituting (7) into (17), the position of displacement front $x_{f}$ is given by

$$
\begin{aligned}
x_{f}= & \frac{f_{w}^{\prime}\left(S_{w f}\right)}{\phi} \\
. & \frac{\sqrt{\left(\mu_{o} \phi L_{e}\right)^{2}+2\left[\mu_{w} a-\mu_{o} f_{w}^{\prime}\left(S_{w f}\right)\right][\phi K \Delta P t]}-\mu_{o} \phi L_{e}}{\mu_{w} a-\mu_{o} f_{w}^{\prime}\left(S_{w f}\right)} .
\end{aligned}
$$

When the front reaches the outlet face, $x_{f}$ equals $L_{e}$; substituting it into (18) and rearranging the equation, the time of water breakthrough can be obtained:

$$
T=\frac{\left[\left(\mu_{w} \phi L_{e} a\right) / f_{w}^{\prime}\left(S_{w f}\right)\right]^{2}-\left(\mu_{o} \phi L_{e}\right)^{2}}{2\left[\mu_{w} a-\mu_{o} f_{w}^{\prime}\left(S_{w f}\right)\right] \phi K \Delta P} .
$$

3.3. Saturation after Water Breakthrough. After the time of water breakthrough, the producing well starts to produce water; according to (9), the pressure drop between the two wells is

$$
\Delta P=\frac{v \mu_{w}}{K} \cdot \frac{x_{f}}{f_{w}^{\prime}\left(S_{w f}\right)} \cdot F\left(S_{w e}\right)
$$

where $S_{w e}$ is the saturation of the producing well, f. After breakthrough, water injection continues, assuming that the front of displacement remains going forward, and the outlet saturation rises from $S_{w f}$ to $S_{w e}$.

Substituting (7) into (13) and taking the derivative, we get

$$
d W(t)=w h v d t=\phi w h L_{e} d \frac{1}{f_{w}^{\prime}\left(S_{w e}\right)} .
$$

Solving (20) and (21) simultaneously, we get

$$
d t=\frac{\mu_{w} L_{e}^{2} \phi}{K \Delta P} \cdot \frac{F\left(S_{w e}\right)}{f_{w}^{\prime}\left(S_{w f}\right)} d \frac{1}{f_{w}^{\prime}\left(S_{w e}\right)} .
$$

Making the integral of (22),

$$
t-T=\frac{\mu_{w} L_{e}^{2} \phi}{K \Delta P} G\left(\frac{1}{f_{w}^{\prime}\left(S_{w e}\right)}\right),
$$

where $G\left(S_{w e}\right)$ is given by

$$
G\left(\frac{1}{f_{w}^{\prime}\left(S_{w e}\right)}\right)=\int_{1 / f_{w}^{\prime}\left(S_{w f}\right)}^{1 / f_{w}^{\prime}\left(S_{w}\right)} \frac{F\left(S_{w e}\right)}{f_{w}^{\prime}\left(S_{w f}\right)} d \frac{1}{f_{w}^{\prime}\left(S_{w e}\right)}
$$

Getting (8) deformed and substituting it into (24),

$$
t-T=\frac{\mu_{w} L_{e}^{2} \phi}{K \Delta P} G\left(\frac{x}{L_{e}} \cdot \frac{1}{f_{w}^{\prime}\left(S_{w}\right)}\right) .
$$

Equation (25) shows the water saturation of any position within the two wells versus injecting time after water breakthrough. Equation (23) is a critical condition of (25) since it refers to the position of the oil well.

\section{Calculation for Multiple Layers}

\subsection{Water Breakthrough in the First (Most Permeable) Layer $i$}

(1) The layer $i$

The time of water breakthrough $T_{i}$ in layer $i$ can be calculated according to (19), and the sweep volume of layer $i$ is calculated by

$$
A_{i}=\frac{\bar{S}_{w}-S_{w c}}{1-S_{o r}-S_{w c}} \cdot w h_{i} L_{e}
$$

where $\bar{S}_{w}$ is as in Welge's equation [7]:

$$
\bar{S}_{w}=S_{w c}+\frac{1}{f_{w}^{\prime}\left(S_{w f}\right)} \text {. }
$$

(2) The other layers, for example, layer $j$

Substituting $T_{i}$ into (18), we can get the front position $x_{f j}$ of layer $j$.

The sweep volume of layer $j$ is

$$
A_{j}=\frac{\bar{S}_{w}-S_{w c}}{1-S_{o r}-S_{w c}} \cdot w h_{j} x_{f j}
$$


(3) Total sweep efficiency

$$
\eta=\frac{A_{i}+\sum_{j=1}^{n-1} A_{j}}{h L_{e}} .
$$

4.2. Water Breakthrough in the Medium (including the Least) Permeable Layer $i$

(1) The layer $i$

It is the same as in Section 4.1(1).

(2) Layers with breakthrough before layer $i$, for example, layer $j$

The time of breakthrough $T_{j}$ in layer $j$ is calculated by (19).

The saturation and water cut of layers that got breakthrough before $T_{i}$ can be calculated by

$$
T_{i}-T_{j}=\frac{\mu_{w} L_{e}^{2} \phi}{K_{j} \Delta P} G\left(\frac{1}{f_{w}^{\prime}\left(S_{w e}\right)}\right) .
$$

After water breakthrough, Welge's equation reforms as follows:

$$
\bar{S}_{w}=S_{w e}+\frac{1-f_{w}\left(S_{w e}\right)}{f_{w}^{\prime}\left(S_{w e}\right)} .
$$

Substituting (31) into (26), the sweep volume of layer $j$ can be obtained.

(3) Layers without breakthrough, for example, layer $k$

This is the same as in Section 4.1(2).

(4) Total sweep efficiency

$$
\eta=\frac{A_{i}+\sum_{j=1}^{m} A_{j}+\sum_{k=1}^{n-m-1} A_{k}}{h L_{e}} .
$$

\section{Case Study and Verification}

Take one injection-production unit of Yaerxia oilfield in Yumen for the case study; the parameters of reservoir and fluid properties are listed in Table 1, and the relative permeability curves are plotted in Figure 3. By analyzing the data of logging, five layers are classified of the main layer $\mathrm{k} \mathrm{g}_{2}{ }^{2-2}$.

There are two kinds of injection programs to be compared with: commingled injection and zonal injection. In commingled injection, all layers are injected and produced under the same pressure condition, while, in zonal injection, the pressure drop and the rate of water flow are different and can be adjusted according to the waterflooding performance. In this case, considering their property differences, five layers are divided into two groups in zonal injection. Put a packer between layer 2 and layer 3 and make layer 1 and layer 2 group I and layers 3 5 group II. In order to achieve a balanced frontal advance, the pressure drop of group I is reduced by half and that of group II is tripled. Use the method above to calculate water frontal position and sweep efficiency of these two injection programs, and the results are verified by a numerical simulator.
TABLE 1: The parameters of reservoir and fluid properties.

\begin{tabular}{lc}
\hline Variables & Value \\
\hline Length of the model, $L_{e}(\mathrm{~m})$ & 200 \\
Width of the model, $w(\mathrm{~m})$ & 100 \\
Thickness of each layer, $h(\mathrm{~m})$ & 1 \\
Pressure drop of the unit, $\Delta P(\mathrm{MPa})$ & 10 \\
Oil viscosity in the reservoir, $\mu_{o}(\mathrm{mPa} \cdot \mathrm{s})$ & 5.6 \\
Water viscosity in the reservoir, $\mu_{w}(\mathrm{mPa} \cdot \mathrm{s})$ & 0.6 \\
Average saturation before breakthrough, $\bar{S}_{w}(\mathrm{f})$ & 0.47 \\
Saturation of front before breakthrough, $S_{w f}(\mathrm{f})$ & 0.33 \\
$F\left(S_{w f}\right)$ before breakthrough, $a(\mathrm{f})$ & 61.5 \\
Residual oil saturation, $S_{o r}(\mathrm{f})$ & 0.30 \\
Irreducible water saturation, $S_{w c}(\mathrm{f})$ & 0.32 \\
$f^{\prime}\left(S_{w f}\right)$ before breakthrough, $(\mathrm{f})$ & 6.65 \\
Porosity of the model, $\phi(\mathrm{f})$ & 0.1 \\
Permeability of layer $1, k_{1}\left(10^{-3} \mu \mathrm{m}^{2}\right)$ & 16.6 \\
Permeability of layer $2, k_{2}\left(10^{-3} \mu \mathrm{m}^{2}\right)$ & 13 \\
Permeability of layer $3, k_{3}\left(10^{-3} \mu \mathrm{m}^{2}\right)$ & 0.8 \\
Permeability of layer $4, k_{4}\left(10^{-3} \mu \mathrm{m}^{2}\right)$ & 2.4 \\
Permeability of layer $5, k_{5}\left(10^{-3} \mu \mathrm{m}^{2}\right)$ & 1.2 \\
\hline
\end{tabular}

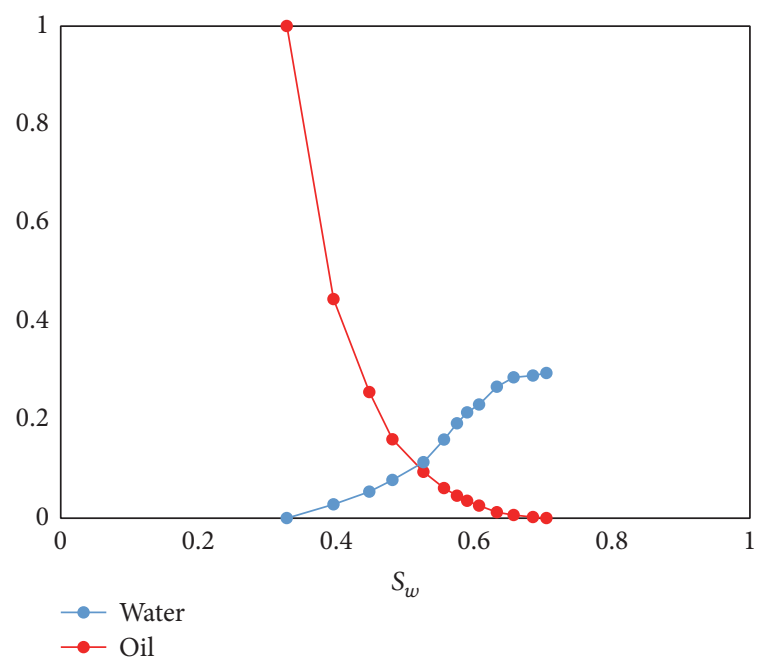

FIGURE 3: Relative permeability curves of the case.

5.1. Water Frontal Position. Use the equations for single layer to calculate the time of water breakthrough of the five layers by (19) for both commingled injection and zonal injection. $T_{1}$ is the breakthrough time of the most permeable layer (layer 1). $T_{1}$ is equal to 214 .1 days in the commingled injection program while it is 428.2 days in the zonal injection program because of the pressure variation. The water frontal position of all layers on $T_{1}$ is calculated by (18). The corresponding sweep volume of each layer is calculated by (26) and (28). The results of equation calculation are listed in Table 2 and results of numerical simulation are listed in Table 3. We plot the water frontal position on $T_{1}$ for the two injection programs (Figures 4 and 5). The calculation results are compared with numerical simulation results, where the former are plotted on the top 
TABLE 2: The results of analytical model in commingled injection and zonal injection.

\begin{tabular}{lcccccc}
\hline Layers & $\begin{array}{c}\text { Commingled injection } \\
\text { Breakthrough } \\
\text { time, } T \text { (day) }\end{array}$ & $\begin{array}{c}\text { Frontal position on } \\
T_{1}, x_{f}(\mathrm{~m})\end{array}$ & $\begin{array}{c}\text { Sweep volume on } \\
T_{1}, A\left(\mathrm{~m}^{3}\right)\end{array}$ & $\begin{array}{c}\text { Breakthrough } \\
\text { time, } T(\text { day })\end{array}$ & $\begin{array}{c}\text { Fonal injection } \\
T_{1}, x_{f}(\mathrm{~m})\end{array}$ & $\begin{array}{c}\text { Sweep volume on } \\
T_{1}, A\left(\mathrm{~m}^{3}\right)\end{array}$ \\
\hline Layer 1 & 214.1 & 200.0 & 7985.7 & 428.1 & 200.0 & 7985.7 \\
Layer 2 & 273.3 & 157.3 & 6280.6 & 546.7 & 157.3 & 6280.6 \\
Layer 3 & 4441.8 & 9.8 & 392.3 & 1480.6 & 48.7 & 2342.1 \\
Layer 4 & 1480.6 & 29.4 & 1174.5 & 493.5 & 173.9 & 6945.4 \\
Layer 5 & 2961.2 & 14.7 & 588.1 & 987.1 & 87.7 & 3502.8 \\
\hline
\end{tabular}

TABLE 3: The results of numerical model in commingled injection and zonal injection.

\begin{tabular}{|c|c|c|c|c|c|c|}
\hline \multirow[b]{2}{*}{ Layers } & \multicolumn{3}{|c|}{ Commingled injection } & \multicolumn{3}{|c|}{ Zonal injection } \\
\hline & $\begin{array}{l}\text { Breakthrough } \\
\text { time, } T \text { (day) }\end{array}$ & $\begin{array}{c}\text { Frontal position on } \\
\qquad T_{1}, x_{f}(\mathrm{~m})\end{array}$ & $\begin{array}{c}\text { Sweep volume on } \\
\quad T_{1}, A\left(\mathrm{~m}^{3}\right)\end{array}$ & $\begin{array}{l}\text { Breakthrough } \\
\text { time, } T \text { (day) }\end{array}$ & $\begin{array}{c}\text { Frontal position on } \\
\qquad T_{1}, x_{f}(\mathrm{~m})\end{array}$ & $\begin{array}{c}\text { Sweep volume on } \\
T_{1}, A\left(\mathrm{~m}^{3}\right)\end{array}$ \\
\hline Layer 1 & 182.0 & 200.0 & 7985.7 & 386.0 & 200.0 & 7985.7 \\
\hline Layer 2 & 231.0 & 158.0 & 6308.7 & 493.0 & 156.0 & 6228.9 \\
\hline Layer 3 & 3567.0 & 12.0 & 479.1 & 1238.0 & 56.0 & 2236.0 \\
\hline Layer 4 & 1214.0 & 31.0 & 1237.7 & 441.0 & 172.0 & 6867.7 \\
\hline Layer 5 & 2502.0 & 16.0 & 638.9 & 874.0 & 86.0 & 3433.9 \\
\hline
\end{tabular}

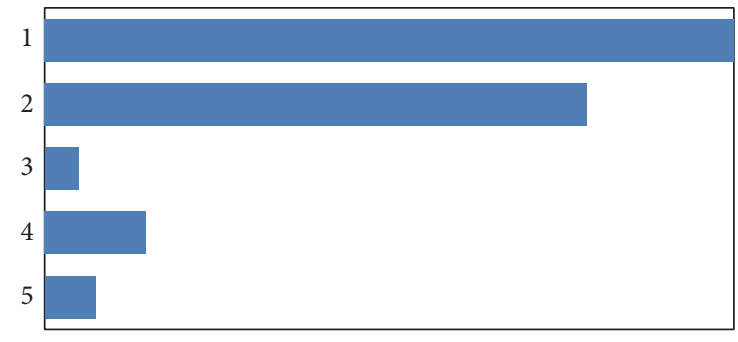

(a) Results of equation calculation

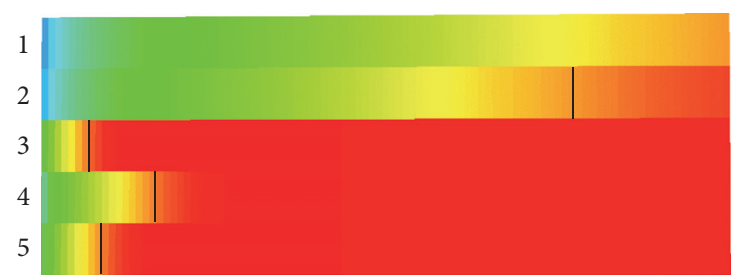

Oil sat.

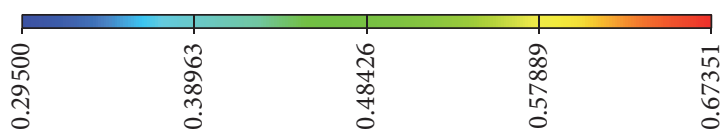

(b) Results of numerical simulation

FIGURE 4: Results comparison of water frontal position of commingled injection on $T_{1}$.

and the latter are plotted right below. The comparisons show that the simulation results match the calculation results well, which verify the equations of single layer.

5.2. Water Cut and Sweep Efficiency. Use the equations for multiple layers to calculate water cut of the model in both of

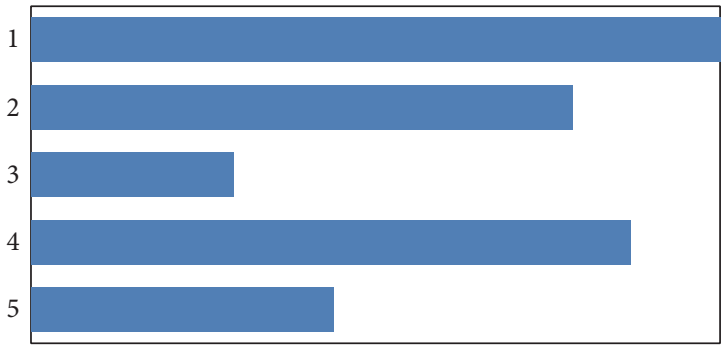

(a) Results of equation calculation

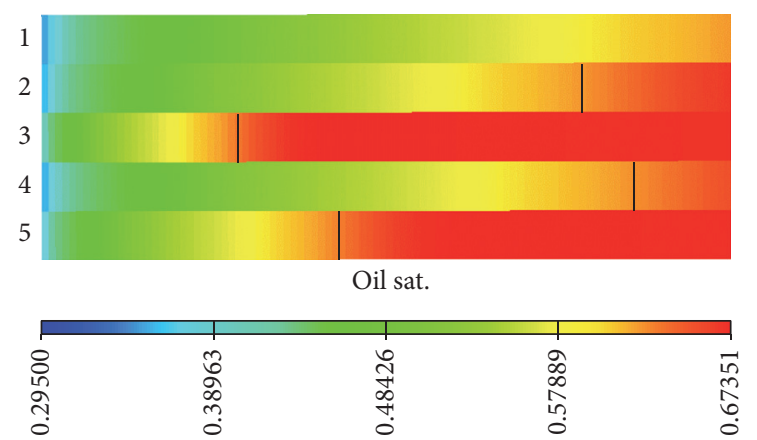

(b) Results of numerical simulation

FIGURE 5: Results comparison of water frontal position of zonal injection on $T_{1}$.

the injection programs by (5) and calculate sweep efficiency by (29) and (32), and oil recovery can be obtained. The curves versus time are shown in Figures 6-8, respectively. The calculation results are compared with numerical simulation results. In the pictures, the solid lines refer to equation calculations and dashed lines refer to numerical simulations. Generally, in oil field, the ultimate sweep efficiency is 


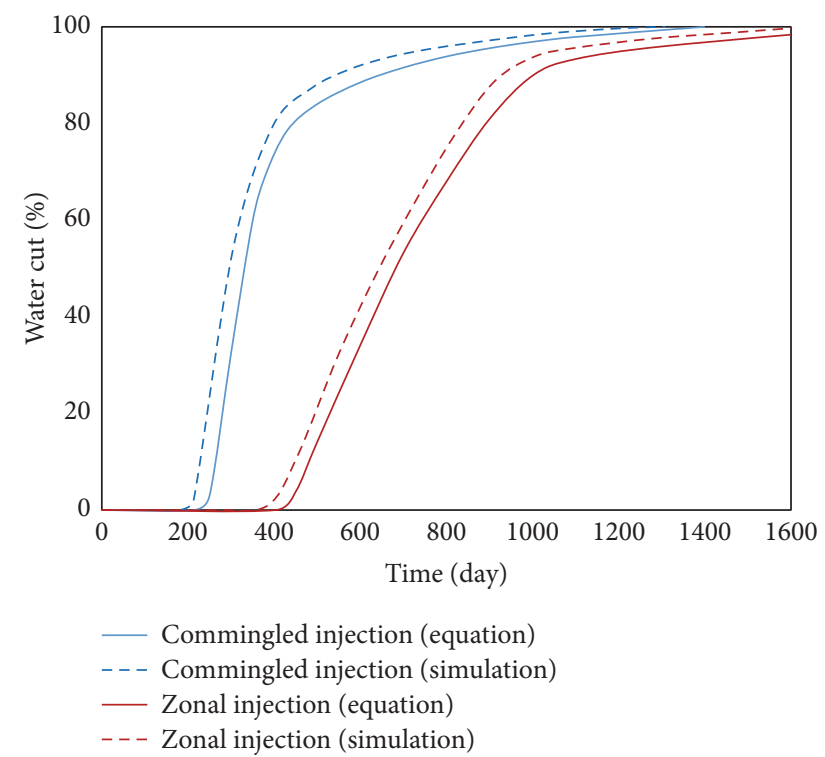

FIGURE 6: Results comparison of water cut versus time in commingled injection and zonal injection.

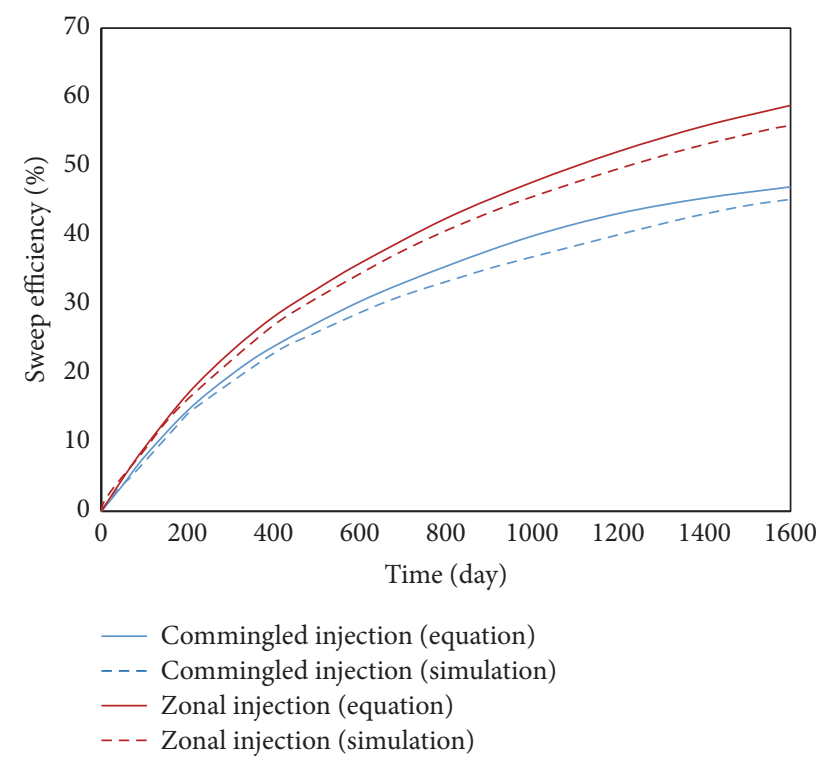

Figure 7: Results comparison of sweep efficiency versus time in commingled injection and zonal injection.

obtained when the water cut of the reservoir reaches $98 \%$. The comparisons show that when water cut of the model comes to $98 \%$, the sweep efficiency of commingled injection is $46.2 \%$, while it is $58.1 \%$ for zonal injection; and the oil recovery of commingled injection is $27.8 \%$, while it is $34.9 \%$ for zonal injection. Figures 9 and 10 illustrate the comparison of water saturation profile between commingled injection and zonal injection after 12 months and 60 months, respectively.

Since the numerical simulator has considered the effect of gravity and capillary forces, the values of water cut calculated by numerical simulation are a bit higher than the

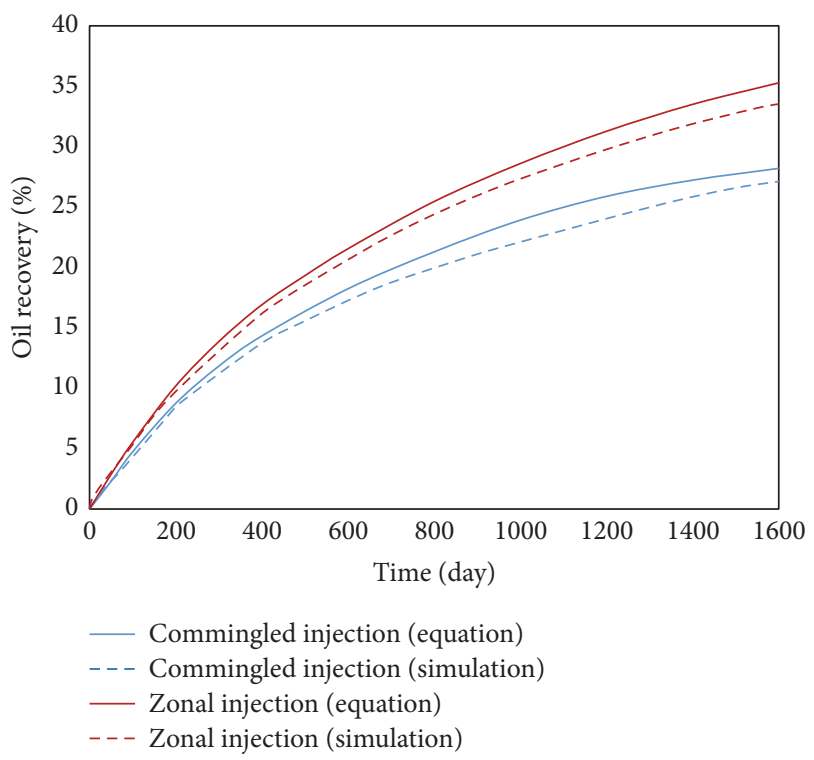

FIGURE 8: Results comparison of oil recovery versus time in commingled injection and zonal injection.

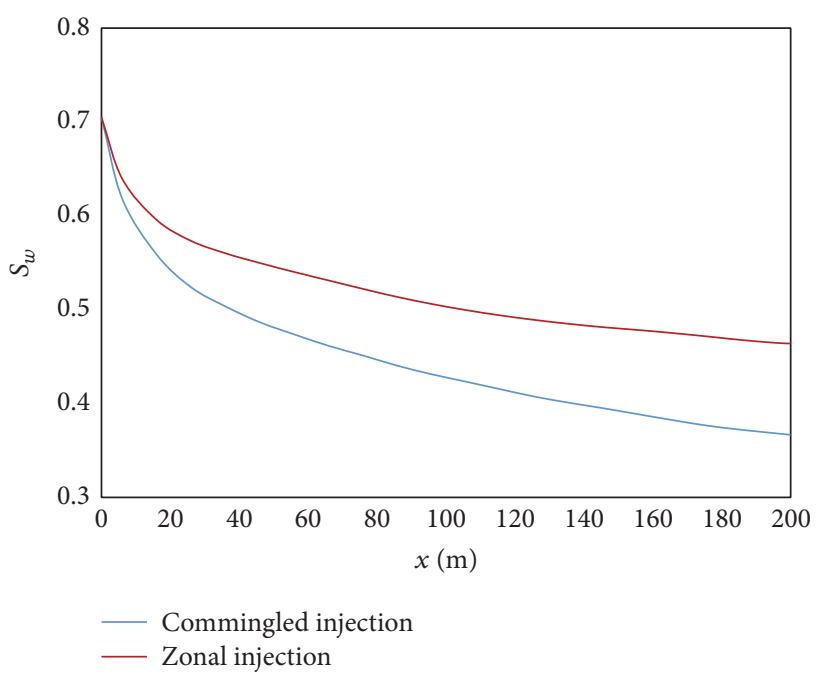

FIGURE 9: Comparison of water saturation between commingled injection and zonal injection after 12 months.

results of equation calculations, and the breakthrough time of the simulation is earlier than that of equation calculation. However, the general trends of these curves are in complete agreement, which verify the equations of multilayers.

5.3. Results Analysis. The comparison results of the two kinds of water injection show the following: in zonal injection, the producing degree of the less permeable layers increases apparently and achieves a much higher sweep efficiency and oil recovery compared with commingled injection. By using zonal injection program, it can restrain the monolayer breakthrough of higher permeable layers and solve interlayer 


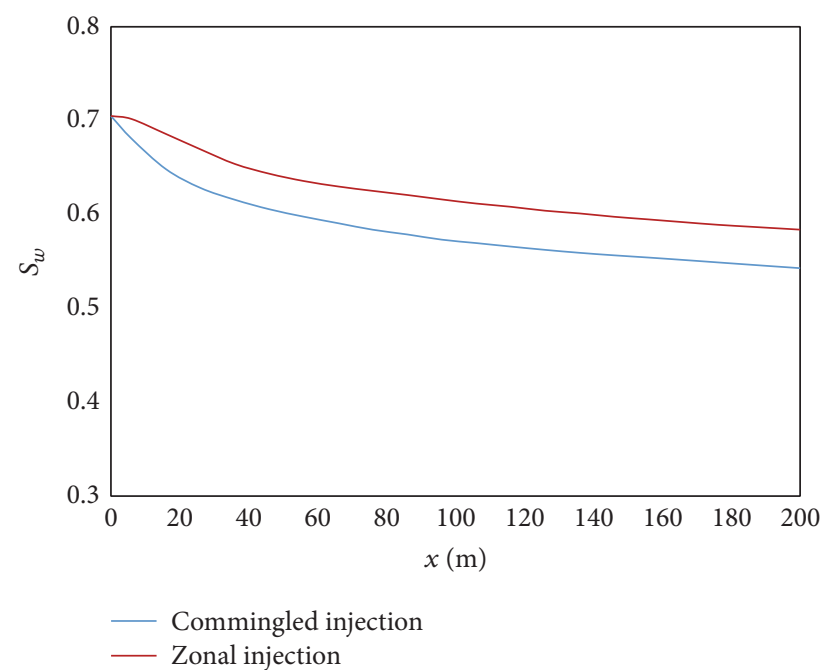

Figure 10: Comparison of water saturation between commingled injection and zonal injection after 60 months.

conflicts. Therefore, a balanced frontal advance is achieved. In oil field development, engineers shall subdivide the layer series with zonal injection based on the reservoir's property differences, which could significantly reduce heterogeneity and postpone the time of water breakthrough. As a consequence, better oil production is achieved.

\section{Conclusion}

(1) An analytical model is developed to explain the waterflooding process in the condition of constant pressure, which substitutes for the condition of constant rate in traditional methods. We deduce the theoretical relationship between the frontal position of waterflooding and water saturation of producing well versus time to describe the dynamic changes of these variables.

(2) By applying this model from one single layer to multilayers, this method gives a quantitative expression of sweep efficiency of the three stages during waterflooding, which can be used to accurately calculate the sweep efficiency of heterogeneous reservoirs and evaluate the degree of waterflooding in multilayer reservoirs.

(3) By comparing the performances of commingled injection and zonal injection in the case study, zonal injection works better than commingled injection in respect of sweep efficiency and oil recovery and has a longer period of water free production. So, it is essential to subdivide the layer series with zonal injection in order to reduce heterogeneity and postpone the time of water breakthrough.

\section{Competing Interests}

The authors declare that there are no competing interests regarding the publication of this paper.

\section{Acknowledgments}

This work was supported by China National Petroleum Co., Ltd., Major Science and Technology Projects (2012E-3304).

\section{References}

[1] N. A. Berruin and R. A. Morse, "Waterflood performance of heterogeneous systems," Journal of Petroleum Technology, vol. 31, no. 7, pp. 829-836, 1979.

[2] M. R. Carlson, "The Effect of reservoir heterogeneity on predicted waterflood performance in the Dodsland field," Journal of Canadian Petroleum Technology, vol. 34, no. 10, pp. 31-38, 1995.

[3] A. K. Permadi, I. P. Yuwono, and A. J. S. Simanjuntak, "Effects of vertical heterogeneity on waterflood performance in stratified reservoirs: a case study in Bangko field, Indonesia," in Proceedings of the SPE Asia Pacific Conference on Integrated Modelling for Asset Management, pp. 157-168, Kuala Lumpur, Malaysia, March 2004.

[4] S. Ghedan, Y. A. Boloushi, K. Khan, and M. B. F. Saleh, "Development of early water breakthrough and effectiveness of water shut off treatments in layered and heterogeneous reservoirs," in Proceedings of the SPE/EAGE Reservoir Characterization and Simulation Conference, SPE-125580-MS, pp. 872-882, Abu Dhabi, UAE, October 2009.

[5] B. Rashid, A. H. Muggeridge, A.-L. Bal, and G. J. J. Williams, "Quantifying the impact of permeability heterogeneity on secondary-recovery performance," SPE Journal, vol. 17, no. 2, pp. 455-468, 2012.

[6] S. E. Buckley and M. C. Leverett, "Mechanism of fluid displacement in sands," Transactions of the AIME, vol. 146, no. 1, pp.107116, 2013.

[7] H. J. Welge, "A simplified method for computing oil recovery by gas or water drive," Journal of Petroleum Technology, vol. 4, no. 4, pp. 91-98, 1952.

[8] W. E. Stiles, "Use of permeability distribution in water flood calculations," Journal of Petroleum Technology, vol. 1, no. 1, pp. 9-13, 2013.

[9] H. Dykstra and R. L. Parsons, "The prediction of oil recovery by waterflooding," in Secondary Recovery of Oil, pp. 160-174, API, Dallas, Tex, USA, 2nd edition, 1950.

[10] A. A. Reznik, R. M. Enick, and S. B. Panvelker, "Analytical extension of the Dykstra-Parsons vertical stratification discrete solution to a continuous, real-time basis," Society of Petroleum Engineers journal, vol. 24, no. 6, pp. 643-655, 1984.

[11] R. Tompang and B. G. Kelkar, "Prediction of waterflood performance in stratified reservoirs," in Proceedings of the Permian Basin Oil and Gas Recovery Conference, pp. 213-224, Midland, Tex, USA, March 1988.

[12] W. N. Hiatt, "Injected-fluid coverage of multi-well reservoirs with permeability stratification," Drilling and Production Practice API-58-165, American Petroleum Institute, New York, NY, USA, 1958.

[13] J. E. Warren, "Prediction of waterflood behavior in a stratified system," Society of Petroleum Engineers Journal, vol. 4, no. 2, pp. 149-157, 1964.

[14] N. A. F. El-Khatib, "Waterflooding performance of communicating stratified reservoirs with log-normal permeability distribution," in Proceedings of the Middle East Oil Show and Conference, Bahrain, March 1997. 
[15] N. A. F. El-Khatib, "The application of Buckley-Leverett displacement to waterflooding in non-communicating stratified reservoirs," in Proceedings of the SPE Middle East Oil Show, pp. 91-102, Manama, Bahrain, March 2001.

[16] Y. F. Zhou, Z. J. Liu, C. J. Mao, X. D. Wang, and B. Zhang, "A new calculation of water displacement efficiency for layered reservoir," Special Oil and Gas Reservoirs, vol. 15, no. 3, pp. 72$75,2008$.

[17] Y. F. Zhou, Y. J. Fang, X. D. Wang, and C. C. Zhou, "A new method for calculating non-piston displacement efficiency in multilayered reservoir with waterflooding," Petroleum Geology \& Recovery Efficiency, vol. 16, no. 1, pp. 86-93, 2009.

[18] N. A. F. El-Khatib, "Waterflooding performance of communicating stratified reservoirs with log-normal permeability distribution," SPE Reservoir Evaluation \& Engineering, vol. 2, no. 6, pp. 542-549, 2013.

[19] N. A. F. El-Khatib, "Waterflooding performance in inclined communicating stratified reservoirs," SPE Journal, vol. 17, no. 1, pp. 31-42, 2012.

[20] R. W. Snyder and H. J. Ramey, "Application of Buckley-Leverett displacement theory to noncommunicating layered systems," Journal of Petroleum Technology, vol. 19, no. 11, pp. 1500-1506, 2013.

[21] A. O. Prince, "Buckley-Leverett displacement theory for waterflooding performance in stratified reservoir," Petroleum \& Coal, vol. 56, no. 3, pp. 267-281, 2014. 


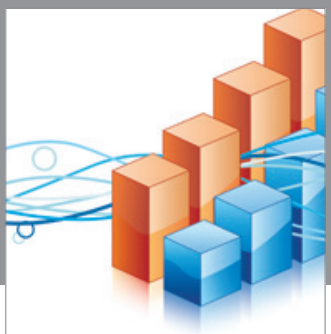

Advances in

Operations Research

vatem alat4

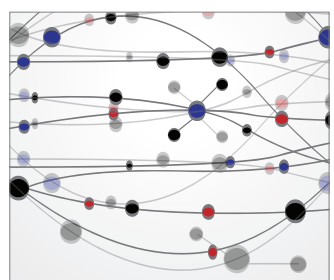

\section{The Scientific} World Journal
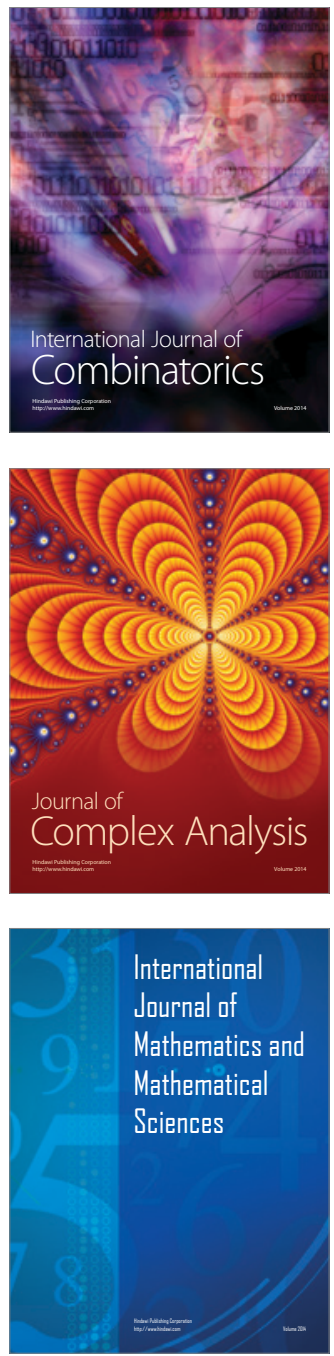
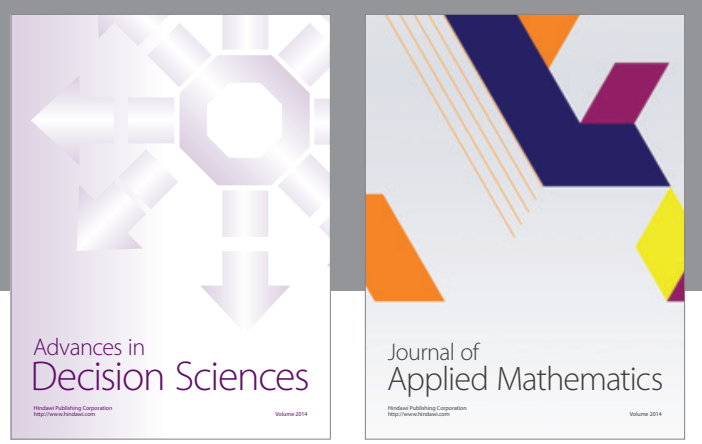

Algebra

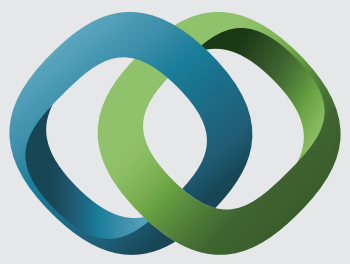

\section{Hindawi}

Submit your manuscripts at

http://www.hindawi.com
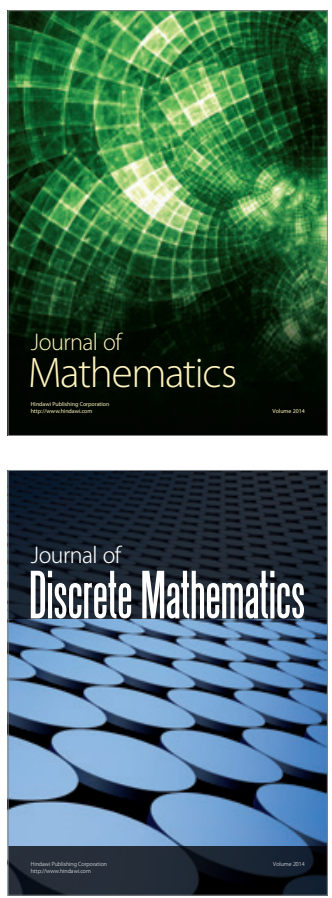

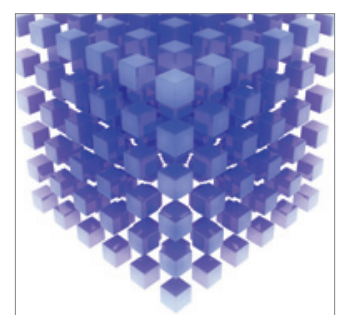

Mathematical Problems in Engineering
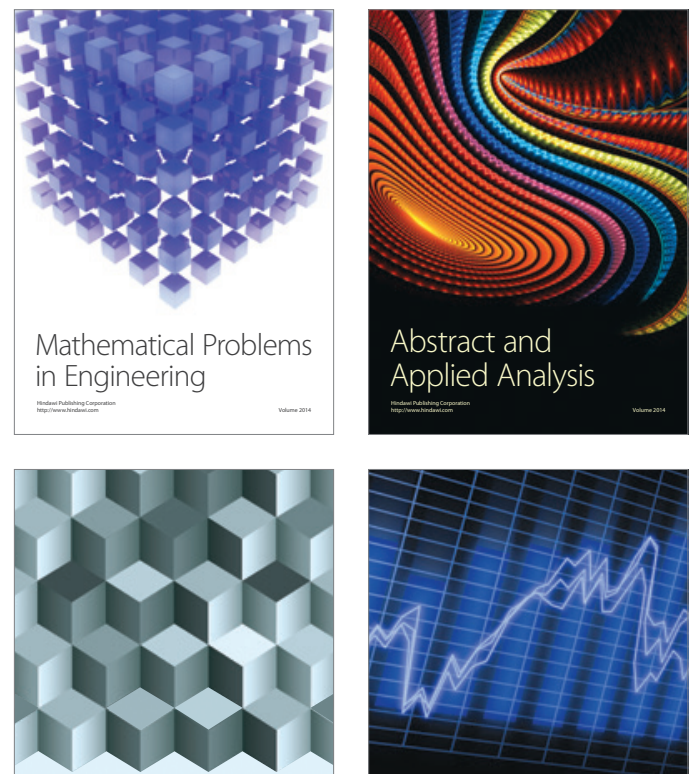

Journal of

Function Spaces

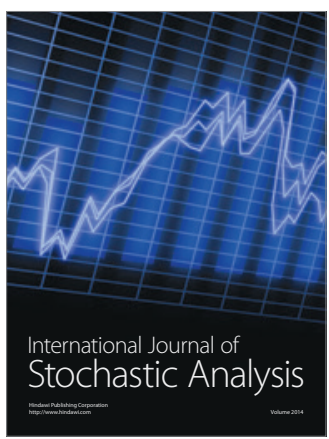

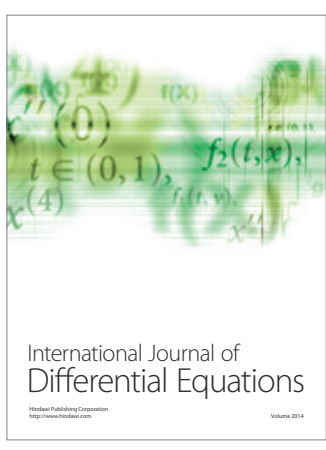
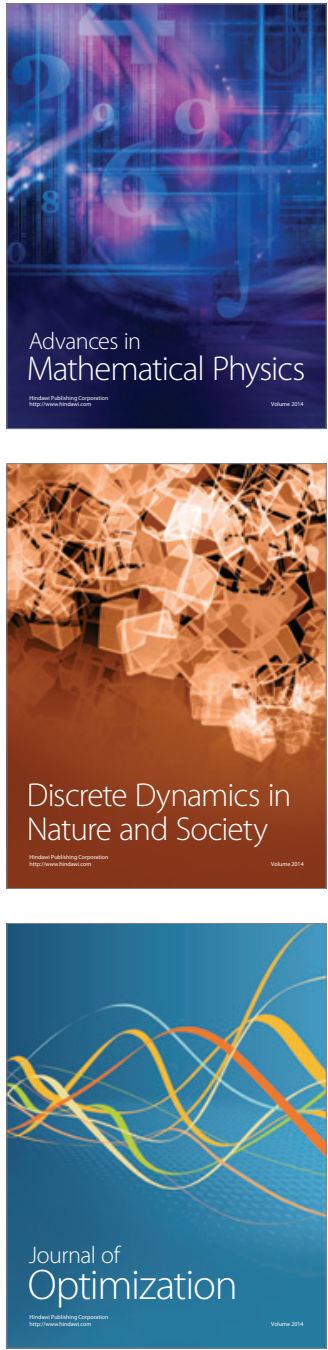